\title{
Effect of supplementary calcium phosphate on plasma gastrointestinal hormones in a double-blind, placebo-controlled, cross-over human study
}

\author{
Ulrike Trautvetter and Gerhard Jahreis* \\ Department of Nutritional Physiology, Institute of Nutrition, Friedrich Schiller University of Jena, \\ Dornburger Straße 24, D-07743 Jena, Germany \\ (Submitted 4 January 2013 - Final revision received 17 June 2013 - Accepted 18 June 2013 - First published online 22 July 2013)
}

\section{Abstract}

Gastrointestinal hormones and $\mathrm{Ca}$ are associated with bone metabolism. The objective of the present human study was to determine the effect of calcium phosphate on the postprandial circulation of gastrointestinal hormones. A total of ten men participated in the present double-blind, placebo-controlled, cross-over study. The participants were divided into two groups. Of these, one group consumed bread enriched with $1 \mathrm{~g} \mathrm{Ca}$ (pentacalcium hydroxy-triphosphate, CaP) daily for 3 weeks. The other group consumed placebo bread. After 2 weeks of washout, the intervention was changed between the groups for another 3 weeks. The subjects consumed a defined diet at the beginning (single administration) and at the end (repeated administration) of the intervention periods, and blood samples were drawn at $0,30,60,120,180$ and $240 \mathrm{~min}$. Between 0 and $30 \mathrm{~min}$, the participants consumed a test meal, with or without CaP. The concentrations of gastrointestinal hormones (glucose-dependent insulinotropic polypeptide, glucagon-like peptide (GLP) 1 and GLP2), insulin and glucose were determined. The AUC of GLP1 (total and active) and GLP2 increased significantly after the repeated $\mathrm{CaP}$ administrations compared with that after placebo administration. The AUC of insulin and glucose showed no differences between the $\mathrm{CaP}$ and placebo administrations. CaP affects the postprandial plasma concentrations of gastrointestinal hormones through the modulation of the intestinal environment, e.g. bile acids and microbiota.

Key words: Calcium phosphate: Gastrointestinal hormones: Human studies: Glucose-dependent insulinotropic polypeptide: Glucagon-like peptides

Glucose-dependent insulinotropic polypeptide (GIP) and glucagon-like peptides 1 and 2 (GLP1 and GLP2) are well-known gastrointestinal hormones $^{(1,2)}$. GIP is a peptide hormone with forty-two amino acid residues and is secreted by K-cells of the small intestine ${ }^{(3,4)}$. GLP1 and GLP2 are thirty-one-amino acid hormones secreted by L-cells of the small intestine ${ }^{(5)}$. The established function of GIP and GLP1 is lowering of glucose levels after ingestion of carbohydrates, proteins and fat and is based on insulin stimulation in the pancreas ${ }^{(1)}$. In addition, both GIP and GLP1 receptors have been found in many other human organs, e.g. brain, bone, adipose tissue and heart ${ }^{(6)}$. GLP2 has several physiological functions such as decreasing gastric acid secretion, inhibiting antral gastric emptying, upregulating intestinal blood flow and exerting trophic effects on the intestinal mucosa as well as positive effects on nutrient absorption $^{(7)}$.

GIP together with GLP1 and GLP2 is associated with bone metabolism. GIP stimulates bone formation by inhibiting the apoptosis of osteoblasts ${ }^{(8)}$. Furthermore, GIP decreases both the activity of alkaline phosphatase in osteoblast-like cells and the expression of collagen type $1^{(9)}$. GLP1 has no direct effect on bone remodelling cells, although indirect mechanisms through the up-regulation of calcitonin have been described $^{(10)}$. A subcutaneous injection of GLP2 in postmenopausal women results in a decrease in the levels of bone resorption markers ${ }^{(11,12)}$.

Since dietary $\mathrm{Ca}$ has beneficial effects on bone metabolism $^{(13,14)}$ and GIP, GLP1 and GLP2 are associated with bone metabolism, the aim of the present study was to determine the interaction between calcium phosphate and gastrointestinal hormones.

\section{Subjects and methods}

\section{Supplement}

For the purposes of supplementation, we used pentacalcium hydroxy-triphosphate $\left(\mathrm{Ca}_{5}\left(\mathrm{PO}_{4}\right)_{3} \mathrm{OH}\right.$; Chemische Fabrik Budenheim KG) in the present study. CaP was incorporated into whole-wheat bread to achieve an additional $\mathrm{Ca}$ intake

Abbreviations: GIP, glucose-dependent insulinotropic polypeptide; GLP1, glucagon-like peptide 1; GLP2, glucagon-like peptide 2.

* Corresponding author: Professor G. Jahreis, fax + 49 3641/949612, email b6jage@uni-jena.de 
of $1 \mathrm{~g} / \mathrm{d}$. The participants consumed approximately $135 \mathrm{~g}$ of this bread daily. Placebo bread was prepared exactly in the same manner, but without the CaP supplement.

\section{Subjects}

The study was conducted between July and September 2010 in the Institute of Nutrition, Department of Nutritional Physiology, at the Friedrich Schiller University, Jena. A total of ten omnivorous men participated in the present doubleblind, placebo-controlled, cross-over study. Eligibility criteria for the participants included age between 20 and 35 years and good physical health. Furthermore, the participants had to stay at the blood-withdrawal centre for at least $5 \mathrm{~h}$ between 07.30 and 12.30 hours. The volunteers were provided with detailed information regarding purpose, course and possible risks involved in the study. The present study was conducted according to the guidelines laid down in the Declaration of Helsinki, and all procedures involving human subjects were approved by the Ethical Committee of the Friedrich Schiller University, Jena (no. 2833-05/10). Written informed consent was obtained from all the subjects. Of the initial ten volunteers, one participant dropped out due to personal reasons. The study flow chart and the baseline characteristics of the nine participants have been published previously ${ }^{(15)}$. Briefly, the participants who completed the study were aged 27 (SD 4) years and had a BMI of $23 \cdot 1(\mathrm{SD} 2 \cdot 3) \mathrm{kg} / \mathrm{m}^{2}$. The main study outcomes comprised blood concentrations of GLP1 (total and active), GLP2, GIP, insulin and glucose. The present trial was registered at www.clinicaltrials.gov (identifier: NCT01296997)

\section{Study design}

The details of the study design have been published previously $^{(15)}$. The participants were divided into two groups. For a period of 3 weeks, one group consumed bread containing $\mathrm{CaP}$, whereas the other group consumed the placebo product. This was followed by a 2 -week washout phase. Thereafter, the intervention was changed between the two groups for a further 3 weeks. Thus, the study design allowed every participant to act as his own control. The intervention periods were divided into two parts. Blood samples were collected from the study participants at the beginning of the study after a single consumption of supplemented bread or placebo (single administration). Thereafter, blood was collected at the end of the 3-week study period, during which the participants consumed either supplemented bread or placebo on a daily basis (repeated administration). Consequently, the study entailed four types of administrations: single CaP administration; single placebo administration; repeated $\mathrm{CaP}$ administration; repeated placebo administration. In addition, the participants consumed a defined diet for $3 \mathrm{~d}$ before each blood sample was collected.

The defined diet, containing the complete food supply for $3 \mathrm{~d}$, was prepared and pre-weighed in the study centre. The subjects were instructed to consume only the food that was provided. Any food residues were weighed and food intake was calculated.

Fasting blood samples were collected from the study participants at the Institute of Transfusion Medicine, Jena University Hospital. Blood samples were drawn after 0, 30, 60, 120, 180 and $240 \mathrm{~min}$, immediately cooled and transported to the study centre.

Between the time points 0 and $30 \mathrm{~min}$, the participants consumed a test meal. The test meal consisted of bread with or without $\mathrm{CaP}$ (according to the intervention), $20 \mathrm{~g}$ butter, $25 \mathrm{~g}$ ham, $15 \mathrm{~g}$ sweet hazelnut spread and a banana. During the $240 \mathrm{~min}$ time point, the participants were allowed to drink water ad libitum.

\section{Sample preparation}

Samples of each food component of the defined diet were frozen and stored at $-20^{\circ} \mathrm{C}$ until analysis.

For the analysis of the gastrointestinal hormones GLP1 (total and active), GIP and GLP2, blood was collected in EDTA-coated tubes, to which dipeptidyl peptidase-IV inhibitor (Millipore) was added before sampling. After centrifugation at $1000 \mathrm{~g}$ for $10 \mathrm{~min}$ at $8^{\circ} \mathrm{C}$, plasma was aliquoted and frozen at $-80^{\circ} \mathrm{C}$. For glucose analysis, blood was collected in EDTA-fluoride tubes, centrifuged at $2000 \boldsymbol{g}$ for $10 \mathrm{~min}$ at $20^{\circ} \mathrm{C}$, aliquoted and analysed. Insulin analysis was performed using serum immediately after blood sampling. Aliquots were frozen at $-80^{\circ} \mathrm{C}$ until analysis.

\section{Food analysis}

The intake of energy, fat, proteins and carbohydrates was verified using the Prodi ${ }^{\circledR} 5.4$ software (Nutri-Science GmbH). For the intake of minerals, the respective contents in the provided foods were analysed instead of using the calculation software. Mineral contents of all the food samples were determined employing the iCAP 6000 ICP Spectrometer (Thermo Scientific). Before analysis, the samples were ashed at $525^{\circ} \mathrm{C}$. The ash was dissolved in $\mathrm{HCl}(25 \%)$ and diluted with distilled water.

\section{Biochemical analyses}

The concentration of total GIP was determined using ELISA (IBL) according to the manufacturer's instructions. The GIP assay was specific to the active form GIP $1-42$ and had a cross-reactivity of about $18 \%$ to the inactive form GIP $3-42$. The intra- and inter-assay CV for GIP were $<5$ and $<7 \%$, respectively. Blood samples collected at time points 30, 60 and 120 min were diluted with a buffer (1:5).

The concentrations of total GLP1 (7-36 and 9-36), active GLP1 (7-36) and GLP2 were determined using ELISA (ALPCO Diagnostics) according to the instructions given in the manual. The total GLP1 assay was $100 \%$ specific to GLP1 $7-36$ and $9-36$ and $<0 \cdot 1 \%$ specific to GLP1 9-37, 7-37 and 1-36, GLP2 and glucagon. The intra- and interassay CV for total GLP1 were $<5$ and $<10 \%$, respectively. The active GLP1 assay was $100 \%$ specific to GLP1 $7-36$ and $<0 \cdot 1 \%$ specific to GLP1 9-36, 9-37, 7-37 and 1-36, GLP2 
and glucagon. The intra- and inter-assay CV for active GLP1 were $<6$ and $<6 \%$, respectively. The GLP2 assay was highly specific to human GLP2 and showed no cross-reactivity with glucagon or GLP1. The intra- and inter-assay CV for GLP2 were $<5$ and $<17 \%$, respectively.

The concentration of glucose was determined by means of the autoanalyser ARCHITECT C16000 (Abbott) according to the methods of the Institute of Clinical Chemistry and Laboratory Medicine, Jena University Hospital. The intra- and inter-assay $\mathrm{CV}$ for glucose were $<2$ and $<3 \%$, respectively.

The concentration of insulin was measured using a twosite sandwich immunoassay employing the ADVIA Centaur test instrument (Siemens) according to the methods of the Institute of Clinical Chemistry and Laboratory Medicine,
Single administration
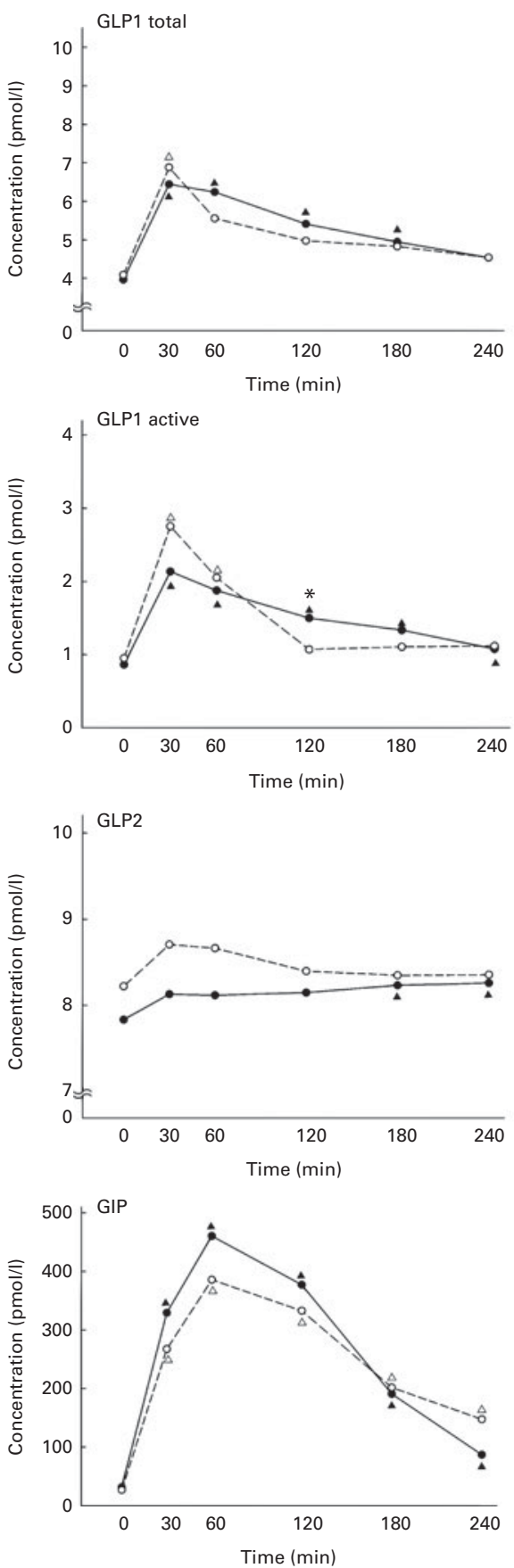

Repeated administration
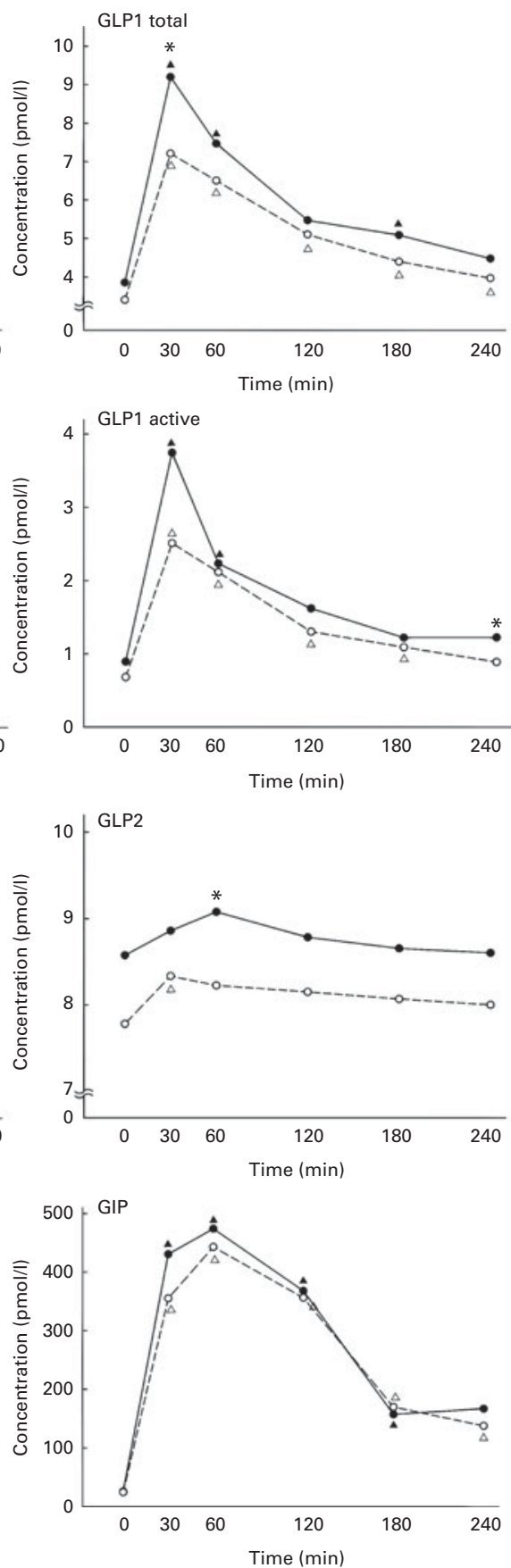

AUC
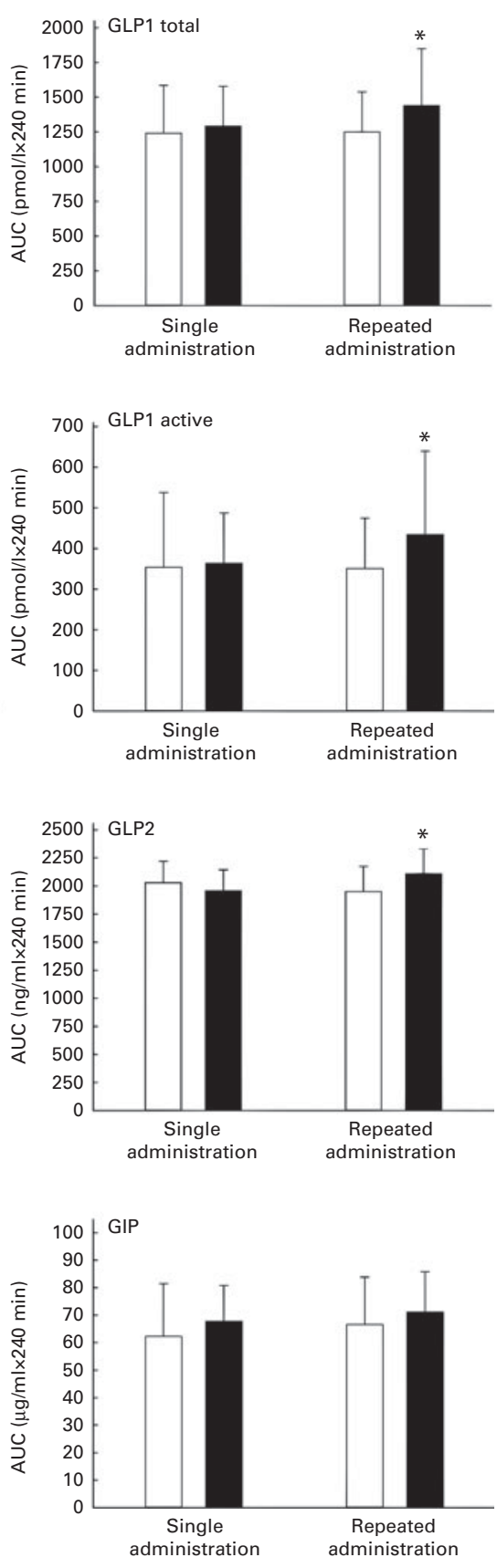

Fig. 1. Concentrations and AUC of glucagon-like peptides (GLP) 1, GLP2 and glucose-dependent insulinotropic polypeptide (GIP). $n$ 9 for total GLP1, active GLP1 and GLP2; $n 8$ for GIP. Values are means; AUC values are means, with standard deviations represented by vertical bars. O, Placebo; $\mathbf{0}$, pentacalcium hydroxy-triphosphate $(\mathrm{CaP})$ supplementation; $\boldsymbol{\Delta}$, significant differences compared with baseline after CaP supplementation $(P \leq 0 \cdot 05)$; $\Delta$, significant differences compared with baseline after placebo administration $(P \leq 0.05)$. ${ }^{*}$ Mean value was significantly different from that of placebo administration $(P \leq 0.05)$. The effects of time and supplementation were tested using paired Student's $t$ test. $\square$, Placebo administration; $\boldsymbol{\square}, \mathrm{CaP}$ administration. 
Jena University Hospital, Friedrich Schiller University Jena. Proinsulin, C-peptide, gastrin-1, glucagon and secretin had no significant effect on insulin values. The intra- and interassay CV for insulin were $<5$ and $<6 \%$, respectively.

\section{Statistical analysis}

Samples from each participant were coded to protect volunteer identity and to mask treatment groups during the analysis. All values given in the tables are expressed as means and standard deviations. For reasons of clarity and comprehensibility, values in the figures are expressed only as means. Statistical analysis was performed using the statistical software package PASW Statistics 18 (SPSS, Inc.). Differences were considered significant at $P \leq 0.05$. The effect of time was tested, comparing with baseline, using paired Student's $t$ test. The effect of supplementation was tested using paired Student's $t$ test. The sample size for $\mathrm{Ca}$ and phosphate was nine. The results for GIP are given for eight subjects due to analytical problems with the concentration of GIP of one subject.

\section{Results}

The nutrient intakes of the test meal and the defined diet have been published previously ${ }^{(15)}$. The additional intakes of $\mathrm{Ca}$ and $\mathrm{P}$ from the CaP bread were 1104 and $519 \mathrm{mg} / \mathrm{d}$, respectively.

\section{Gastrointestinal hormones}

The concentrations and the AUC of total GLP1, active GLP1, GLP2 and GIP are shown in Fig. 1.

Total glucagon-like peptide 1. The concentration of total GLP1 increased after single CaP administration significantly from 0 to $30 \mathrm{~min}(P=0.025), 60 \mathrm{~min} \quad(P=0.002), 120 \mathrm{~min}$ $(P=0.002)$ and $180 \mathrm{~min}(P=0.043)$. The concentration of total GLP1 after placebo administration increased after $30 \mathrm{~min}(P=0.039)$ compared with that at $0 \mathrm{~min}$. After the repeated $\mathrm{CaP}$ administrations, the concentration of total GLP1 increased significantly after $30 \mathrm{~min}(P=0 \cdot 013), 60 \mathrm{~min}$ $(P=0.012)$ and $180 \mathrm{~min}(P=0.006)$ compared with that at 0 min. After placebo administration, the concentration of total GLP1 increased after $30 \mathrm{~min} \quad(P=0.011), 60 \mathrm{~min}$ $(P<0.000), \quad 120 \mathrm{~min} \quad(P=0.001), 180 \mathrm{~min} \quad(P=0.004)$ and $240 \mathrm{~min}(P=0.024)$ compared with that at $0 \mathrm{~min}$. At $30 \mathrm{~min}$, the concentration of total GLP1 was significantly higher after CaP supplementation than after placebo administration $(P=0 \cdot 005)$. The AUC of total GLP1 was significantly higher after the repeated $\mathrm{CaP}$ administrations than after placebo administration ( $P=0 \cdot 022$; Fig. 1$)$.

Active glucagon-like peptide 1 . The concentration of active GLP1 increased significantly after single CaP administration after $30 \mathrm{~min}(P=0.003), 60 \mathrm{~min}(P=0.005), 120 \mathrm{~min}$ $(P=0.000), 180 \mathrm{~min}(P=0.007)$ and $240 \mathrm{~min}(P=0.034) \mathrm{com}-$ pared with that at $0 \mathrm{~min}$. After placebo administration, there was a significant increase after $30 \mathrm{~min}(P=0.030)$ and $60 \mathrm{~min}(P=0.025)$. Besides, the concentration of active GLP1 at $120 \mathrm{~min}(P=0 \cdot 026)$ was significantly higher after
$\mathrm{CaP}$ administration in comparison with that after placebo administration. The repeated $\mathrm{CaP}$ administrations resulted in an increased concentration of active GLP1 after $30 \mathrm{~min}$ $(P=0.023)$ and $60 \mathrm{~min}(P=0.047)$ compared with that at 0 min. After repeated placebo administrations, the concentration increased significantly after $30 \mathrm{~min}(P=0 \cdot 003), 60 \mathrm{~min}$ $(P=0.006), 120 \mathrm{~min}(P<0.000)$ and $180 \mathrm{~min}(P=0.016)$ in comparison with that at $0 \mathrm{~min}$. The concentration after $\mathrm{CaP}$ supplementation was significantly higher at time point $240 \mathrm{~min}(P=0.043)$ compared with that after placebo supplementation. The AUC after the repeated $\mathrm{CaP}$ administrations was significantly higher than that after placebo administration $(P=0.044)$ (Fig. 1).

Glucagon-like peptide 2. After single CaP administration, there was a slight, but significant increase in the concentration of GLP2 after $180 \mathrm{~min}(P=0.010)$ and $240 \mathrm{~min}(P=0.048)$ compared with that at $0 \mathrm{~min}$. The single placebo as well as the repeated $\mathrm{CaP}$ administrations led to no significant changes. The repeated placebo administrations led to a significant increase after $30 \mathrm{~min}(P=0 \cdot 023)$. The AUC of GLP2 after the repeated $\mathrm{CaP}$ administrations was significantly higher than that after placebo administration $(P=0.032)$ (Fig. 1).

Glucose-dependent insulinotropic polypeptide. Both the single and repeated administrations led to an increase in the concentration of GIP (Fig. 1). There were no differences between the $\mathrm{CaP}$ and placebo administrations.

\section{Glucose and insulin}

Both the single and repeated administrations led to an increase in the concentrations of glucose and insulin (Fig. 2). The AUC of glucose and insulin showed no significant differences between the placebo and CaP supplementation.

\section{Discussion}

$\mathrm{Ca}$ is often associated with bone health in the literature. Calcium phosphate, in particular, is often discussed in this regard due to its intestinal actions with respect to the formation of amorphous calcium phosphate and the precipitation of intestinal substances such as bile or fatty acids ${ }^{(16-18)}$. In the present study, the effect of $\mathrm{CaP}$ on the secretion of gastrointestinal hormones was determined.

To the best of our knowledge, there are no human intervention studies available in the literature examining the role of calcium phosphate in the secretion of gastrointestinal hormones. Only Lorenzen et al. ${ }^{(19)}$ investigated the effect of dietary $\mathrm{Ca}$ or supplementary $\mathrm{Ca}$ (calcium carbonate) intake on postprandial fat metabolism, appetite and subsequent energy intake. Although the study showed a significant interaction between meals and time of GLP1 secretion, according to the authors, this association was due to an inexplicably high concentration of GLP1 after $60 \mathrm{~min}$ and was not influenced by the $\mathrm{Ca}$ supplement ${ }^{(19)}$. Nevertheless, $\mathrm{Ca}$ and the gastrointestinal hormones GIP, GLP1 and GLP2 are associated with bone metabolism ${ }^{(8,10,20,21)}$. There are two means by which Ca could influence the secretion of gastrointestinal hormones after meal ingestion: directly following the consumption of 
Single administration
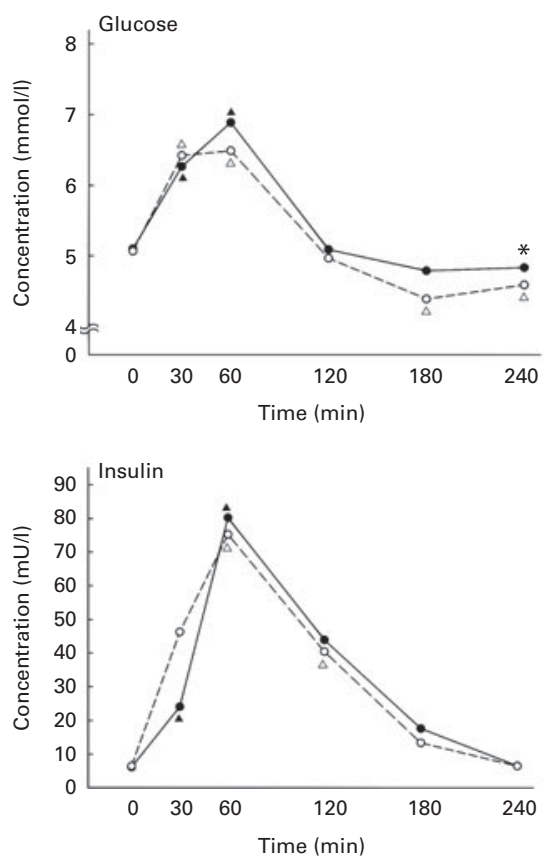

Repeated administration
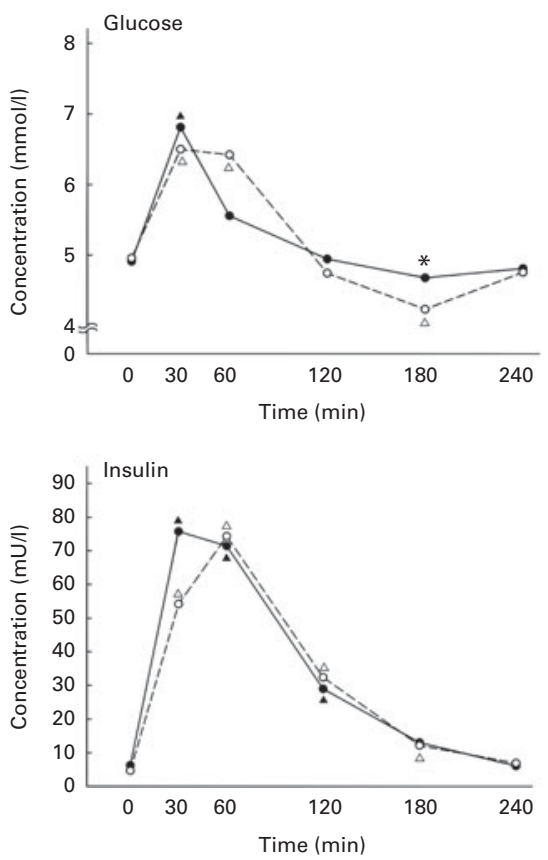

AUC
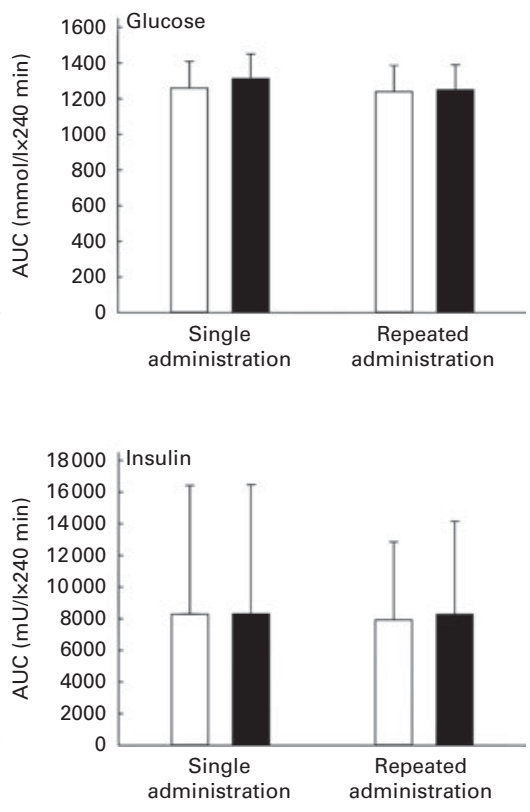

Fig. 2. Concentrations and AUC of glucose and insulin. Values are means; AUC values are means $(n$ ), with standard deviations represented by vertical bars. O, Placebo; - pentacalcium hydroxy-triphosphate $(\mathrm{CaP})$ supplementation; $\boldsymbol{\Delta}$, significant differences compared with baseline after CaP supplementation $(P \leq 0.05) ; \Delta$, significant differences compared with baseline after placebo administration $(P \leq 0.05)$. The effects of time and supplementation were tested using paired Student's $t$ test. $\square$, Placebo administration; $\mathbf{\square}$, CaP administration.

a Ca-rich meal and indirectly through the modulation of the intestinal environment after long-term $\mathrm{Ca}$ administration. Tsukiyama et $a l .{ }^{(9)}$ determined that GIPR knockout mice had similar concentrations of plasma Ca before meal ingestion but higher levels after meal ingestion compared with normal mice. The authors assumed that GIP directly links dietary Ca to $\mathrm{Ca}$ deposition in bone ${ }^{(9)}$. This mechanism has not been explained to date, and it is not known whether Ca influences the secretion of gastrointestinal hormones or vice versa. Furthermore, Toyota et $a l .{ }^{(22)}$ elucidated that hypercalcaemia might have stimulatory effects on glucose-induced GIP release. These two publications point to a direct effect of $\mathrm{Ca}$ on the secretion of gastrointestinal hormones. However, based on the results of the present study, a direct effect can be excluded, as there was no difference between the single $\mathrm{CaP}$ and placebo administrations. Moreover, the supplementation did not lead to a hypercalcaemic status ${ }^{(15)}$.

Significant increases in the concentrations of gastrointestinal hormones were observed after the repeated CaP administrations. Thus, an indirect effect of CaP is plausible. Several studies have shown the ability of CaP to form an amorphous calcium phosphate complex that is able to precipitate intestinal substances, such as fatty acids and bile acids ${ }^{(17,23,24)}$. The formation and precipitation lead to several physiological changes in the human gut, e.g. modulation of microbiota and bile acid profile ${ }^{(23,25-28)}$. Katsuma et al. ${ }^{(29)}$ observed that bile acids promote the secretion of GLP1 in a murine enteroendocrine cell line STC-1 through a G protein-coupled receptor, TGR5. Furthermore, in a randomised controlled study carried out by Beysen et l. $^{(30)}$, the effect of bile acid sequestrants on glucose metabolism was determined in patients with type 2 diabetes. Bile acid sequestrants (e.g. colesevelam and cholestyramine) form non-absorbable complexes with bile acids in the gastrointestinal tract, which leads to the interruption of their enterohepatic circulation, thereby promoting their faecal excretion ${ }^{(31)}$. Bile acid sequestrants are used as therapeutic agents for lowering LDL-cholesterol levels. In the study of Beysen et al. ${ }^{(30)}$, the bile acid sequestrant colesevelam increased the concentrations of total GLP1 and GIP and the synthesis of cholesterol and bile acids and decreased the concentration of fibroblast growth factor-19. The authors assumed that bile acids activate the TGR5 receptor, which is expressed in enteroendocrine L-cells, and stimulate the secretion of GLP1. The authors supposed either a link between the composition of the bile acid pool or the change to a more hydrophilic bile acid pool by colesevelam to be responsible for these mechanisms ${ }^{(31)}$. In the present study, CaP acted as a bile acid sequestrant. In fact, the ability of amorphous calcium phosphate to precipitate bile acids in the intestine has been reported previously by in vitro ${ }^{(24,28)}$ and in vivo ${ }^{(18)}$ studies. Furthermore, in a double-blind, placebo-controlled, cross-over study, Ditscheid et al. ${ }^{(25)}$ showed a significant increase in the excretion of bile acids after CaP supplementation compared with that after placebo supplementation and linked this to the precipitation of bile acids to amorphous calcium phosphate. The indirect effect of $\mathrm{CaP}$ via amorphous calcium phosphate is supported by the fact that only GLP1 and GLP2, but not GIP, were influenced significantly. The formation of amorphous calcium phosphate and the interaction with bile acids increase during 
the gastrointestinal passage ( $\mathrm{pH}$ dependent $)^{(32)}$. Therefore, $\mathrm{CaP}$ may influence only the gastrointestinal hormones that are secreted in the distal small intestine (GLP1 and GLP2).

Another explanation for the increased secretion of gastrointestinal hormones after repeated $\mathrm{CaP}$ supplementation is the modulation of the intestinal microbiota ${ }^{(23,26)}$. Through a change in the microbiota, there may be an increase in SCFA production. SCFA can stimulate the release of GLP2 in the gut of patients with short bowel syndrome ${ }^{(33)}$. Additionally, there are hints in the literature that point to an association between dietary prebiotics and a rise in the concentrations of gastrointestinal hormones due to an increase of colonic fermentation products ${ }^{(34,35)}$

The changes in the secretion of gastrointestinal hormones after repeated $\mathrm{CaP}$ supplementation did not affect insulin and glucose metabolism. Both insulin and glucose showed a normal postprandial response, as published in the literature $^{(36-38)}$. Different gastrointestinal hormones have diverse target sites and, thus, it is likely that this modulation affects actions such as bone metabolism.

In conclusion, this is the first human study to investigate the effect of supplemental CaP on the postprandial concentrations of GIP, GLP1 and GLP2. From the present results, we conclude that CaP stimulates the secretion of gastrointestinal hormones through the modulation of the intestinal environment.

\section{Acknowledgements}

The authors thank Dr Lars Müller, Manja Dittrich and Ute Helms for their technical and scientific assistance. They also thank Nasim Kroegel for English language editing.

The authors thank VCI (Verband der Chemischen Industrie e.V.) for providing financial support and for supplying the supplement. VCI had no role in the design, analysis or writing of this article.

Neither of the authors had a personal or financial conflict of interest.

U. T. conducted the research, analysed the data, performed the statistical analysis and wrote the manuscript. U. T. and G. J. designed the research and had primary responsibility for the final content. All authors were responsible for the critical revision of the manuscript.

\section{References}

1. Phillips LK \& Prins JB (2011) Update on incretin hormones Ann N Y Acad Sci 1243, E55-E74.

2. Estall JL \& Drucker DJ (2006) Glucagon-like peptide-2. Annu Rev Nutr 26, 391-411.

3. Buchan AMJ, Polak JM, Capella C, et al. (1978) Electronimmunocytochemical evidence for the $\mathrm{K}$ cell localization of gastric inhibitory polypeptide (GIP) in man. Histochemistry 56, 37-44

4. Moody AJ, Thim L \& Valverde I (1984) The isolation and sequencing of human gastric inhibitory peptide (GIP). FEBS Lett 172, 142-148.

5. Eissele R, Goke R, Willemer S, et al. (1992) Glucagon-like peptide- 1 cells in the gastrointestinal tract and pancreas of rat, pig and man. Eur J Clin Invest 22, 283-291.
6. Seino Y, Fukushima M \& Yabe D (2010) GIP and GLP-1, the two incretin hormones: similarities and differences. J Diabetes Invest 1, 8-23.

7. Jeppesen PB, Lund P, Gottschalck IB, et al. (2009) Short bowel patients treated for two years with glucagon-like peptide 2 (GLP-2): compliance, safety, and effects on quality of life. Gastroenterol Res Pract 2009, article ID 425759.

8. Yamada Y, Miyawaki K, Tsukiyama K, et al. (2006) Pancreatic and extrapancreatic effects of gastric inhibitory polypeptide. Diabetes 55, S86-S91.

9. Tsukiyama K, Yamada Y, Yamada C, et al. (2006) Gastric inhibitory polypeptide as an endogenous factor promoting new bone formation after food ingestion. Mol Endocrinol 20, 1644-1651.

10. Yamada C, Yamada Y, Tsukiyama K, et al. (2008) The murine glucagon-like peptide-1 receptor is essential for control of bone resorption. Endocrinology 149, 574-579.

11. Henriksen DB, Alexandersen P, Bjarnason NH, et al. (2003) Role of gastrointestinal hormones in postprandial reduction of bone resorption. J Bone Miner Res 18, 2180-2189.

12. Henriksen DB, Alexandersen P, Hartmann B, et al. (2007) Disassociation of bone resorption and formation by GLP-2 - a 14-day study in healthy postmenopausal women. Bone 40, 723-729.

13. Heaney RP, Recker RR, Watson P, et al. (2010) Phosphate and carbonate salts of calcium support robust bone building in osteoporosis. Am J Clin Nutr 92, 101-105.

14. Bonjour JP (2011) Calcium and phosphate: a duet of ions playing for bone health. J Am Coll Nutr 30, 438S-448S.

15. Trautvetter U, Kiehntopf M \& Jahreis G (2013) Postprandial effects of calcium phosphate supplementation on plasma concentration-double-blind, placebo-controlled cross-over human study. Nutr J 12, 30.

16. Lapre JA, De Vries HT \& Van der Meer R (1991) Dietary calcium phosphate inhibits cytotoxicity of fecal water. $\mathrm{Am} \mathrm{J}$ Physiol Gastrointest Liver Physiol 261, G907-G912.

17. Ditscheid B, Keller S \& Jahreis G (2005) Cholesterol metabolism is affected by calcium phosphate supplementation in humans. J Nutr 135, 1678-1682.

18. Van der Meer R, Welberg JWM, Kuipers F, et al. (1990) Effects of supplemental dietary calcium on the intestinal association of calcium, phosphate, and bile-acids. Gastroenterology 99, 1653-1659.

19. Lorenzen JK, Nielsen S, Holst JJ, et al. (2007) Effect of dairy calcium or supplementary calcium intake on postprandial fat metabolism, appetite, and subsequent energy intake. Am J Clin Nutr 85, 678-687.

20. Reid IR, Cornish J \& Baldock PA (2006) Nutrition-related peptides and bone homeostasis. J Bone Miner Res 21, 495-500.

21. Wong IP, Baldock PA \& Herzog H (2010) Gastrointestinal peptides and bone health. Curr Opin Endocrinol Diabetes Obes 17, 44-50.

22. Toyota T, Nakanome C, Akai H, et al. (1982) Release of gastric inhibitory polypeptide (GIP) during calcium infusion and in hyperparathyroidism. Regul Pept $\mathbf{4}, 1-12$.

23. Trautvetter U, Ditscheid B, Kiehntopf M, et al. (2012) A combination of calcium phosphate and probiotics beneficially influences intestinal lactobacilli and cholesterol metabolism in humans. Clin Nutr 31, 230-237.

24. Govers MJ, Termont DS, Van Aken GA, et al. (1994) Characterization of the adsorption of conjugated and unconjugated bile acids to insoluble, amorphous calcium phosphate. J Lipid Res 35, 741-748. 
25. Ditscheid B, Keller S \& Jahreis G (2009) Faecal steroid excretion in humans is affected by calcium supplementation and shows gender-specific differences. Eur J Nutr 48, 22-30.

26. Bovee-Oudenhoven IM, Wissink ML, Wouters JT, et al. (1999) Dietary calcium phosphate stimulates intestinal lactobacilli and decreases the severity of a salmonella infection in rats. J Nutr 129, 607-612.

27. Govers MJ, Termont DS, Lapre JA, et al. (1996) Calcium in milk products precipitates intestinal fatty acids and secondary bile acids and thus inhibits colonic cytotoxicity in humans. Cancer Res 56, 3270-3275.

28. Van der Meer R, Termont DS \& De Vries HT (1991) Differential effects of calcium ions and calcium phosphate on cytotoxicity of bile acids. Am J Physiol 260, G142-G147.

29. Katsuma S, Hirasawa A \& Tsujimoto G (2005) Bile acids promote glucagon-like peptide-1 secretion through TGR5 in a murine enteroendocrine cell line STC-1. Biochem Biophys Res Commun 329, 386-390.

30. Beysen C, Murphy EJ, Deines K, et al. (2012) Effect of bile acid sequestrants on glucose metabolism, hepatic de novo lipogenesis, and cholesterol and bile acid kinetics in type 2 diabetes: a randomised controlled study. Diabetologia 55, 432-442.

31. Brufau G, Stellaard F, Prado K, et al. (2010) Improved glycemic control with colesevelam treatment in patients with type 2 diabetes is not directly associated with changes in bile acid metabolism. Hepatology 52, 1455-1464.
32. Van der Meer R \& De Vries HT (1985) Differential binding of glycine-conjugated and taurine-conjugated bile-acids to insoluble calcium-phosphate. Biochem J 229, 265-268.

33. Tappenden KA, Albin DM, Bartholome AL, et al. (2003) Glucagon-like peptide- 2 and short-chain fatty acids: a new twist to an old story. $J$ Nutr 133, 3717-3720.

34. Diamant M, Blaak EE \& De Vos WM (2011) Do nutrient-gutmicrobiota interactions play a role in human obesity, insulin resistance and type 2 diabetes? Obes Rev 12, 272-281.

35. Cani PD, Lecourt E, Dewulf EM, et al. (2009) Gut microbiota fermentation of prebiotics increases satietogenic and incretin gut peptide production with consequences for appetite sensation and glucose response after a meal. Am J Clin Nutr 90, 1236-1243.

36. Frost GS, Brynes AE, Dhillo WS, et al. (2003) The effects of fiber enrichment of pasta and fat content on gastric emptying, GLP-1, glucose, and insulin responses to a meal. Eur J Clin Nutr 57, 293-298.

37. Greenway F, O'Neil CE, Stewart L, et al. (2007) Fourteen weeks of treatment with Viscofiber increased fasting levels of glucagon-like peptide-1 and peptide-YY. J Med Food 10, $720-724$.

38. Thomsen C, Rasmussen O, Lousen T, et al. (1999) Differential effects of saturated and monounsaturated fatty acids on postprandial lipemia and incretin responses in healthy subjects. Am J Clin Nutr 69, 1135-1143. 